\title{
Childhood sexual abuse and non-suicidal self-injury: meta-analysis
}

E. David Klonsky and Anne Moyer

\section{Background}

Many theorists posit that childhood sexual abuse has a central role in the aetiology of self-injurious behaviour. Studies that report statistically significant associations between a history of such abuse and self-injury are cited to support this view.

\section{Aims}

A meta-analysis was conducted to determine systematically the magnitude of the association between childhood sexual abuse and self-injurious behaviour.

\section{Method}

Forty-five analyses of the association were identified. Effect sizes were converted to a standard metric and aggregated.

\section{Results}

The relationship between childhood sexual abuse and selfinjurious behaviour is relatively small (mean weighted aggregate $\phi=0.23)$. This figure may be inflated owing to publication bias. In studies that statistically controlled for psychiatric risk factors, childhood sexual abuse explained little or no unique variance in self-injurious behaviour.

\section{Conclusions}

Theories that childhood sexual abuse has a central or causal role in the development of self-injurious behaviour are not supported by the available empirical evidence. Instead, it appears that the two are modestly related because they are correlated with the same psychiatric risk factors.

\section{Declaration of interest}

None.
Self-injurious behaviour can be defined as the causing of intentional, direct damage to one's body tissue without suicidal intent. ${ }^{1}$ Common examples include cutting and burning of the skin. ${ }^{2-5}$ Because such behaviour is associated with suicide and psychiatric disorders, ${ }^{3,6,7}$ and because its treatment can be challenging, ${ }^{8-11}$ it has attracted substantial attention in both the clinical and research literature. Although the clinical correlates and functions of selfinjurious behaviour have been studied extensively, ${ }^{7,12-15}$ little is known about its aetiology.

Many theorise that childhood sexual abuse has a primary aetiological role. For example, van der Kolk et al ${ }^{16}$ (p. 1669) wrote that childhood trauma such as sexual abuse 'contributes heavily to the initiation of self-destructive behaviour'. Wonderlich et $a l^{17}$ (p. 203) suggested that individuals subjected to childhood sexual abuse 'engage in a broad array of self-destructive behaviors that may serve to reduce emotional distress associated with their abuse'. Noll et $a^{18}$ (p. 1467) proposed that sexually abused individuals who self-injure 'may be reenacting the abuse perpetrated on them'. Cavanaugh ${ }^{19}$ (pp. 97, 99) described self-injurious behaviour as a 'manifestation of sexual abuse'. Stone ${ }^{20}$ implicated sexual abuse by a male relative in the development of such behaviour. More recently, Yates ${ }^{21}$ theorised that sexual abuse and other childhood traumas cause emotional and relational vulnerabilities which in turn create the need for self-injurious behaviour as a maladaptive coping strategy.

Those who advocate an aetiological role of childhood sexual abuse point to the numerous studies that document a relationship between histories of such behaviour and self-injurious abuse. However, to characterise accurately the empirical relationship between the two variables it is necessary to take into account studies that find small or no associations, in addition to studies that find a positive association. As previous efforts to review the empirical literature on this topic have taken a narrative approach, ${ }^{22}$ the meta-analysis reported here was conducted to systematically quantify the research findings on the relationship between a history of childhood sexual abuse and the development of self-injurious behaviour.

\section{Method}

\section{Inclusion and exclusion criteria}

Studies reporting original research findings regarding the relationship between a history of childhood sexual abuse and self-injurious behaviour were included in this review. Studies in which all participants had histories of childhood sexual abuse or all participants had histories of self-injurious behaviour were excluded, since such studies could not provide measures of association between the two (e.g. Noll et $a^{18}$ ). Studies examining self-injurious behaviour with suicidal intent, or that did not distinguish between such behaviour with and without suicidal intent, were also excluded from the meta-analysis (e.g. Romans et al; ${ }^{23}$ Sansone et al; ${ }^{24}$ Brown et $a l^{25}$ ). Studies examining participants with developmental disabilities or psychosis were excluded. Finally, studies that examined childhood abuse without distinguishing between physical, sexual and other forms of abuse were excluded (e.g. Brodsky et $a l^{26}$ ).

\section{Search strategy}

To identify appropriate studies, a literature search was conducted using three database sources: PubMed, PsycINFO, and the Web of Knowledge Science Citation and Social Science Citation Indices. Owing to ambiguity regarding terminology, multiple keywords were identified, and the following search string was used: (selfinjury or self-injurious behaviour OR deliberate self-harm OR self-mutilation OR self-mutilative behaviour OR self-destructive) AND (sex abuse OR sexual abuse). Studies published up to the end of June 2006 were surveyed.

Our search strategy yielded 156 empirical English-language studies and these were obtained for further inspection regarding inclusion and exclusion criteria. Of these, 100 were excluded (Fig. 1).

The remaining 56 studies met inclusion criteria. However, for 16 of these there was not enough information to extract an effect size regarding the abuse-behaviour association and efforts to 


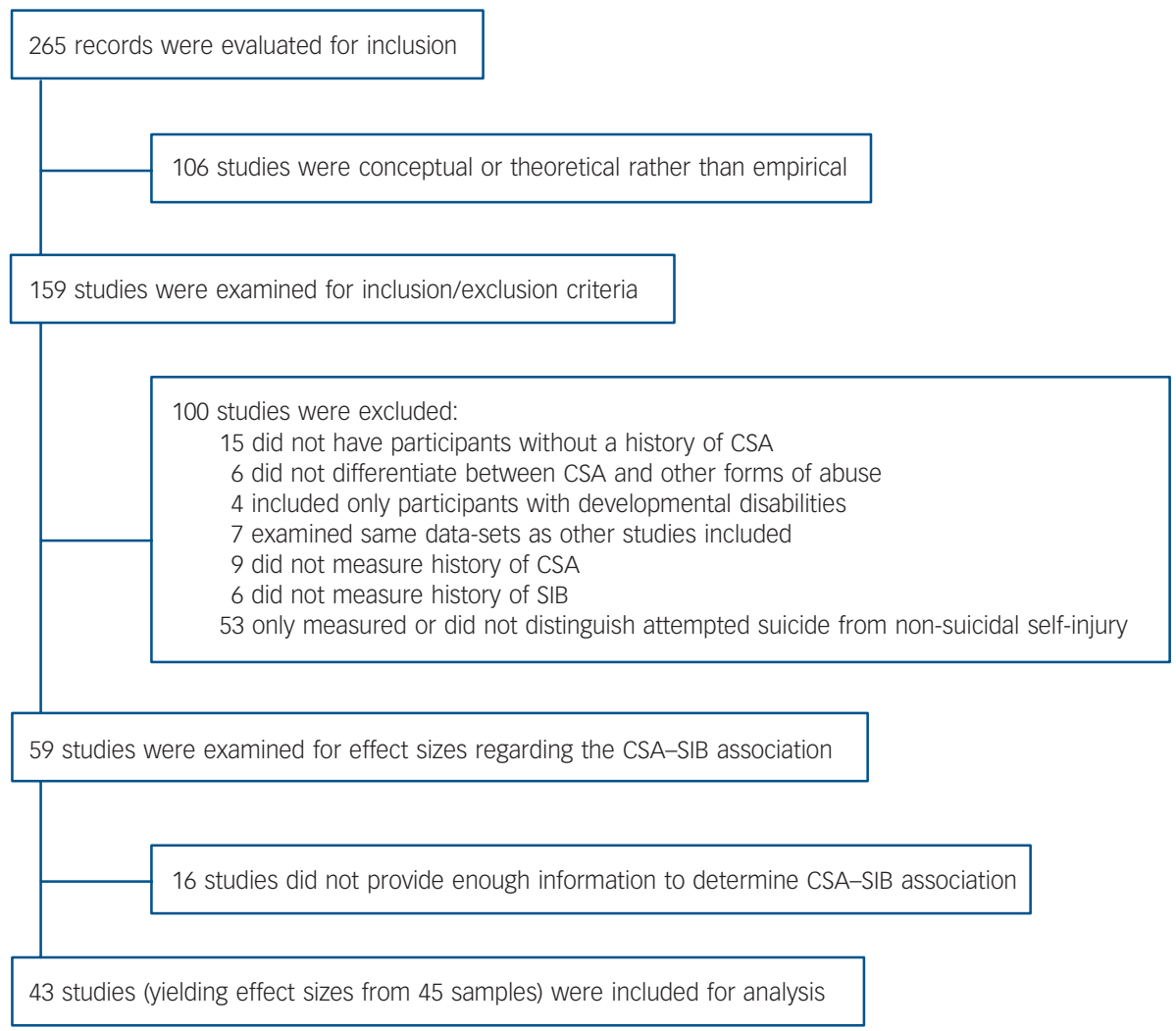

Fig. 1 QUOROM (Quality of Reporting of Meta-analyses) diagram (CSA, childhood sexual abuse; SIB, self-injurious behaviour).

obtain the data from study authors were not successful. The remaining 40 studies with known effect sizes were retained for inclusion in the meta-analysis. We inspected the reference sections of studies meeting inclusion criteria to locate additional relevant studies that might have been missed by our search strategy; only three additional studies meeting inclusion criteria could be located, all of which were published before $1990 .{ }^{27-29}$ Thus we concluded that our search strategy was sufficiently comprehensive and inclusive. Incorporating the three additional studies yielded a total of 43 studies $^{5,16,17,27-66}$ that met full inclusion criteria and were retained for the meta-analysis. These 43 studies contributed effect sizes from 45 independent samples.

\section{Data analysis and study details}

For each study in the meta-analysis, effect sizes indicating the relationship between childhood sexual abuse and self-injurious behaviour were extracted or converted to phi coefficient effect sizes. A phi coefficient is a measure of the degree of association between two dichotomous variables and its interpretation is comparable to other correlation coefficients. Methodological details of the 43 studies and 45 samples - including sample size, sample type and demographic variables - are presented in online Table DS1. Meta-analytic analyses were conducted with Comprehensive Meta-Analysis version 2.2.023 (Biostat; Englewood, New Jersey, USA). The effect sizes were examined for heterogeneity and the mean weighted aggregate effect size was computed, adopting a fixed-effects model in the case of a homogeneous distribution of effect sizes and a random-effects model in the case of a heterogeneous distribution. Potential continuous moderators (age, percentage female) of the aggregate effect size were examined with meta-regression and a categorical moderator (type of sample) was examined with an analogue of an analysis of variance procedure appropriate for effect size data. A fixed-effects model was used when the factors adequately explained the heterogeneity. When additional heterogeneity remained, a mixed-effects model was used.

\section{Results}

Table DS1 presents the results from 45 samples regarding the relationship between history of childhood sexual abuse and selfinjurious behaviour. The mean weighted aggregate phi coefficient was 0.23 (95\% CI $0.20-0.26)$ using a random effects model, and was significantly different from $0(P<0.001)$. Phi coefficients ranged from 0.01 to 0.45 and the distribution exhibited significant heterogeneity $(Q=90.47, P<0.001)$. Moderator analyses indicated that the magnitude of phi was not related to sample age or gender. Using a mixed-effects model, the type of sample was a significant moderator of the relationship between sexual abuse and self-injurious behaviour $(Q(1,39)=5.34, P<0.05)$. This relationship was stronger for the clinical samples $(n=31 ; \phi=0.24)$ than for the non-clinical samples $(n=10 ; \phi=0.18)$. For this latter analysis, four samples were excluded because they could not be discretely classified as either non-clinical or clinical. ${ }^{17,30-32}$

We examined the likelihood of publication bias by plotting the standard error as a function of Fisher's $Z$ for each of the 45 effect sizes. On inspection the pattern indicated a lack of symmetry, whereby there were fewer smaller studies with smaller effect sizes in the group located for the review. Kendall's tau was significant $(0.25, P<0.01)$, indicating an association between the treatment 
effect and the standard error. Similarly, Egger's test of the intercept was significant $(t=4.82, P<0.001)$. Although these tests are useful for detecting a relationship between sample size and effect size, they cannot isolate the cause, only one of which is publication bias. The fail-safe $N$ indicated that 5462 null studies would need to be located and included to nullify the effect found.

All studies that controlled for psychological risk factors found either minimal or negligible unique associations between childhood sexual abuse and self-injurious behaviour. Because different studies controlled for different variables, these results cannot be statistically aggregated and are thus described here qualitatively. Gratz et $a l^{45}$ found that the abuse-behaviour relationship became non-significant when controlling for dissociation and several family environment variables (i.e. physical abuse, insecure attachment, emotional neglect and childhood separation), although the relationship remained marginally significant when analyses were limited to female participants. In contrast, Martin et $a l^{51}$ found that the relationship remained statistically significant for male but not female participants when controlling for depression, hopelessness and family functioning. Zoroglu et al ${ }^{65}$ found that childhood sexual abuse maintained a statistically significant association with self-injurious behaviour when controlling for dissociation, although the childhood variables neglect, physical abuse and emotional abuse all maintained larger unique associations with such behaviour than did sexual abuse.

All remaining studies that controlled for psychosocial variables found non-significant relationships between childhood sexual abuse and self-injurious behaviour. Evren \& Evren $^{39}$ found that childhood physical abuse (but not sexual abuse) maintained a significant association with self-injurious behaviour when controlling for demographic, family history, and clinical variables. Zlotnick et $a l^{64}$ found that the abuse-behaviour association was no longer significant when controlling for dissociation, alexithymia and self-destructive behaviours. Zweig-Frank et al ${ }^{66}$ reported that the association became non-significant when controlling for family environment variables and a diagnosis of borderline personality disorder. Likewise, in Gladstone et $a l^{41}$ the correlation became non-significant when controlling for borderline personality disorder. Finally, in Parker et $a l^{54}$ the association became nonsignificant when controlling for maternal depression, suicidal ideation, current drug use and suicide attempt history.

\section{Discussion}

Our meta-analysis examined the association between a history of childhood sexual abuse and the development of self-injurious behaviour. Across 45 samples, the aggregate phi coefficient was 0.23 , indicating a relatively small relationship between the two. These results suggest that childhood sexual abuse accounts for no more than $5 \%$ of the variance in the development of self-injurious behaviour. Therefore it is unlikely that childhood sexual abuse has a primary role in the development or maintenance of such behaviour.

Significantly, studies with smaller sample sizes tended to report larger relationships. For example, the median phi coefficient for samples with more than 125 participants was 0.21 $(n=22)$, compared with a median of $\phi=0.33(n=23)$ for samples with 125 or fewer participants. This result suggests the possibility of a bias towards publishing studies with statistically significant results, since studies with smaller sample sizes require larger effect sizes to achieve statistical significance. Indeed, formal analyses found evidence of publication bias, suggesting that smaller studies with positive findings were more likely to be published than smaller studies with null or negative findings.
Finally, childhood sexual abuse appears to explain little or no unique variance in self-injurious behaviour. In studies that controlled for variables such as family environment, dissociation, alexithymia, hopelessness and borderline personality disorder, the abuse-behaviour relationship became minimal or negligible. ${ }^{39,45,51,54,64,66}$ In addition, this relationship was stronger in clinical samples, in which multiple psychiatric risk factors are likely to be present. Taken as a whole, the pattern of findings suggests that childhood sexual abuse might be best conceptualised as a proxy risk factor for self-injurious behaviour. ${ }^{67}$ In other words, the two might be associated because they are correlated with the same psychiatric risk factors, as opposed to there being a unique or aetiological link between them. At the same time, in some cases childhood sexual abuse might contribute to the initiation of self-injurious behaviour through mediating variables such as depression, anxiety and self-derogation, each of which is known to relate to both childhood sexual abuse and self-injurious behaviour. ${ }^{13,68,69}$

\section{Future directions}

Variability in the conceptual and operational definitions used by the studies included in the meta-analysis suggests directions for future research. For example, self-injurious behaviour can manifest in many ways and it is possible that the method, frequency, medical severity or other aspects of such behaviour could moderate the abuse-behaviour relationship. Future research should examine this possibility. In addition, meta-analytic data indicate that the association between childhood sexual abuse and psychopathological symptoms tends to be larger for more severe forms of abuse. ${ }^{68}$ Future studies should therefore give consideration to abuse parameters indicative of increased severity (e.g. coercion, frequency, relation to perpetrator, penetration). Initial attempts to examine the relationship of severity parameters to self-injurious behaviour have yielded mixed results. ${ }^{22,34,51,63,66}$ If the most severe forms of childhood sexual abuse are examined, it is possible that the association with self-injurious behaviour might be larger than that reported in this meta-analysis. In the absence of such evidence, however, theories that childhood sexual abuse is a primary cause of such behaviour lack empirical justification.

E. David Klonsky, PhD, Anne Moyer, PhD, Department of Psychology, Stony Brook University, Stony Brook, New York, USA

Correspondence: Dr E. David Klonsky, Department of Psychology, Stony Brook University, Stony Brook, New York 11794-2500, USA. Tel: +1 631632 7801; fax: +1 631632 7876; email: E.David.Klonsky@stonybrook.edu

First received 1 Sep 2006, final revision 17 May 2007, accepted 10 Jul 2007

\section{Acknowledgements}

Preparation of this paper was supported in part by National Research Service Award MH67299 from the National Institute of Mental Health and funding from the Office of the Vice President of Research at Stony Brook University.

\section{References}

1 Pattison EM, Kahan J. The deliberate self-harm syndrome. Am J Psychiatry 1983; 140: 867-72.

2 Favazza AR, Conterio K. Female habitual self-mutilators. Acta Psychiatr Scand 1989; 79: 283-9.

3 Langbehn DR, Pfohl B. Clinical correlates of self-mutilation among psychiatric inpatients. Ann Clin Psychiatry 1993; 5: 45-51. 
4 Herpertz S. Self-injurious behavior: psychopathological and nosological characteristics in subtypes of self-injurers. Acta Psychiatr Scand 1995; 91: 57-68.

5 Nijman HLI, Dautzenberg M, Merckelbach HLGJ, Jung P, Wessel I, del Campo JA. Self-mutilating behavior in psychiatric inpatients. Eur Psychiatry 1999; 14: 4-10.

6 Tantam D \& Whittaker J. Personality disorder and self-wounding. Br J Psychiatry 1992; 161: 451-64.

7 Skegg S. Self-Harm. Lancet 2005; 366, 1471-83.

8 Feldman MD. The challenge of self-mutilation: a review. Compr Psychiatry 1988; 29: 252-69.

9 Favazza AR. Repetitive self-mutilation. Psychiatr Ann 1992; 22: 60-3.

10 Scheel KR. The empirical basis of Dialectical Behavior Therapy: summary, critique, and implications. Clin Psychol: Sci Pract 2000; 7: 68-96.

11 Kapur N. Management of self-harm in adults: which way now? $\mathrm{Br} J$ Psychiatry 2005; 187: 497-9.

12 Gratz KL. Risk factors for and functions of deliberate self-harm: an empirical and conceptual review. Clin Psychol Sci Pract 2003; 10, 192-205.

13 Klonsky ED, Oltmanns TF, Turkheimer E. Deliberate self-harm in a nonclinical population: prevalence and psychological correlates. Am J Psychiatry 2003; 160: $1501-8$.

14 Nock MK, Prinstein MJ. Contextual features and behavioral functions of self mutilation among adolescents. J Abnorm Psychol 2005; 114: 140-6.

15 Klonsky ED. The functions of deliberate self-injury: a review of the evidence. Clin Psychol Rev 2007; 27: 226-39.

16 van der Kolk, BA, Perry JC, Herman JL. Childhood origins of self-destructive behavior. Am J Psychiatry 1991; 148: 1665-72.

17 wonderlich S, Donaldson MA, Carson DK, Staton D, Gertz L, Leach LR, Johnson M. Eating disturbance and incest. J Interpers Violence 1996; 11: 195-207.

18 Noll JG, Horowitz LA, Bonanno GA, Trickett PK, Putnam FW. Revictimization and self-harm in females who experienced childhood sexual abuse. $J$ Interpers Violence 2003; 18: 1452-71.

19 Cavanaugh RM. Self-mutilation as a manifestation of sexual abuse in adolescent girls. J Pediatr Adolesc Gynecol 2002; 15, 97-100.

20 Stone $\mathrm{MH}$. A psychodynamic approach: some thoughts on the dynamics and therapy of self-mutilating borderline patients. J Personal Disord 1987; 1: 3479.

21 Yates TM. The developmental psychopathology of self-injurious behavior: compensatory regulation in posttraumatic adaptation. Clin Psychol Rev 2004 24: $35-74$.

22 Mina EES, Gallop RM. Childhood sexual and physical abuse and adult selfharm and suicidal behaviour: a literature review. Can J Psychiatry 1998; 43 793-800.

23 Romans SE, Martin JL, Anderson JC, Herbison GP, Mullen PE. Sexual abuse in childhood and deliberate self-harm. Am J Psychiatry 1995; 152: 1336-42.

24 Sansone RA, Gaither GA \& Barclay J. Childhood trauma and somatic preoccupation in adulthood among a sample of psychiatric inpatients. Psychosomatics 2002; 43: 86.

25 Brown LK, Houck CD, Hadley WS. Self-cutting and sexual risk among adolescents in intensive psychiatric treatment. Psychiatr Serv 2005; 56: 216-18.

26 Brodsky BS, Cloitre M, Dulit RA. Relationship of dissociation to self-mutilation and childhood abuse in borderline personality disorder. Am J Psychiatry 1995; 152: 1788-92.

27 Carroll J, Schaffer D, Spensley J, Abramowitz SI. Family experiences of selfmutilating patients. Am J Psychiatry 1980; 137: 852-3.

28 Craine LS, Henson CE, Colliver JA, MacLean DG. Prevalence of a history of sexual abuse among female psychiatric patients in a state hospital system. Hosp Community Psychiatry 1988; 39: 300-4.

29 Schwartz RH, Cohen P, Hoffman NG, Meeks KE. Self-harm behaviors (carving) in female adolescent drug abusers. Clin Pediatr 1989; 28: 340-6.

30 Wonderlich SA, Crosby RD, Mitchell JE, Thompson KM, Redlin J, Demuth G, Smyth J, Haseltine B. Eating disturbance and sexual trauma in childhood and adulthood. Int J Eat Disord 2001; 30: 401-21.

31 Swanston HY, Nunn KP, Oates RK, Tabbutt JS, O'Toole BI. Hoping and coping in young people who have been sexually abused. Eur Child Adolesc Psychiatry 1999; 8: 134-42.

32 Tyler KA, Whitback LB, Hoyt VR, Johnson KD. Sell-mutilation and homeless youth: the role of family abuse, street experiences and mental disorders. $J$ Res Adolesc 2003; 13: 457-71.
33 Bierer LM, Yehuda R, Schmeidler J, Mitropoulou V, New AS, Silverman JM, Seiver L. Abuse and neglect in childhood: Relationship to personality disorder diagnoses. CNS Spectr 2003; 8: 737-54.

34 Boudewyn AC, Liem JH. Childhood sexual abuse as a precursor to depression and self-destructive behavior in adulthood. J Trauma Stress 1995; 8: 445-59.

35 Briere J, Gil E. Self-mutilation in clinical and general population samples: prevalence, correlates, and functions. Am J Orthopsychiatry 1998; 68: 609-20.

36 Briere J, Zaidi LY. Sexual abuse histories and sequelae in female psychiatric emergency room patients. Am J Psychiatry 1989; 146: 1602-6.

37 Brown L, Russell J, Thornton C, Dunn S. Dissociation, abuse, and the eating disorders: evidence from an Australian population. Aust NZ J Psychiatry 1999; 33: 521-8.

38 Darche MA. Psychological factors differentiating self-mutilating and non-selfmutilating adolescent inpatient females. Psychiatr Hosp 1990; 21: 31-5.

39 Evren C, Evren B. Self-mutilation in substance-dependent patients and relationship with childhood abuse and neglect, alexithymia and temperament and character dimensions of personality. Drug Alcohol Depend 2005; 80: $15-22$.

40 Favaro A, Santonastaso P. Different types of self-injurious behavior in bulimia nervosa. Compr Psychiatry 1999; 40: 57-60.

41 Gladstone GL, Parker GB, Wilhelm K, Malhi GS, Wilhelm K, Austin MP. Characteristics of depressed patients who report childhood sexual abuse. Am J Psychiatry 1999; 156: 431-7.

42 Gladstone GL, Parker GB, Mitchell PB, Malhi GS, Wilhelm K, Austin MP. Implications of childhood trauma for depressed women: an analysis of pathways from childhood sexual abuse to deliberate self-harm and revictimization. Am J Psychiatry 2004; 161: 1417-25.

43 Gleaves DH, Eberenz KP. Eating disorders and additional psychopathology in women: the role of prior sexual abuse. J Child Sex Abus 1993; 2: 71-80.

44 Gratz KL. Risk factors for deliberate self-harm among female college students: The role and interaction of childhood maltreatment, emotional inexpressivity, and affect intensity/reactivity. Am J Orthopsychiatry 2006; 76 238-50.

45 Gratz KL, Conrad SD \& Roemer L. Risk factor for deliberate self-harm among college students. American Journal of Orthopsychiatry 2002; 72: 128-40.

46 Jarvis TJ, Copeland J. Child sexual abuse as a predictor of psychiatric comorbidity and its implications for drug and alcohol treatment. Drug Alcohol Depend 1997; 49: 61-9.

47 Joyce PR, McKensie JM, Mulder RT, Luty SE, Sullivan PF, Miller Al, Kennedy MA. Genetic, developmental, and personality correlates of self-mutilation in depressed patients. Aust NZ J Psychiatry 2006; 40: 225-9.

48 Kroll J, Fiszdon J, Crosby RD. Childhood abuse and three measures of altered states of consciousness (dissociation, absorption, and mysticism) in a female outpatient sample. J Personal Disord; 1996; 10: 345-54.

49 Lipschitz DS, Winegar RK, Nicolau AL, Hartnick E, Wolfson M, Southwick SM. Perceived abuse and neglect as risk factors for suicidal behavior in adolescent inpatients. J Nerv Ment Dis 1999; 187: 32-9.

50 Low G, Jones D, MacLeod A, Power M, Duggan C. Childhood trauma, dissociation, and self-harming behaviour: a pilot study. Br J Med Psychol 2000; 73: 269-78.

51 Martin G, Bergen HA, Richardson AS, Roeger L, Allison S. Sexual abuse and suicidality: Gender differences in a large community sample of adolescents. Child Abuse Neg 2004; 28: 491-593.

52 Matsumoto T, Azekawa T, Yamaguchi A, Asami T, Isaki E. Habitual selfmutilation in Japan. Psychiatry Clin Neurosci 2004; 58: 191-8.

53 Paivio SC, Mcculloch CR. Alexithymia as a mediator between childhood trauma and self-injurious behaviors. Child Abuse Negl 2004; 28: 339-54.

54 Parker G, Malhi G, Mitchell P, Kotze B, Wilhelm K, Parker K. Self-harming in depressed patients: pattern analysis. Aust NZ J Psychiatry 2005; 39: 899-906.

55 Pettigrew J, Burcham J. Effects of childhood sexual abuse in adult female psychiatric patients. Aust NZ J Psychiatry 1997; 31: 208-13.

56 Rodriguez-Srednicki O. Childhood sexual abuse, dissociation, and adult selfdestructive behavior. J Child Sex Abus 2001; 10: 75-90.

57 Rose SM, Peabody CG, Stratigeas B. Undetected abuse among intensive case management clients. Hosp Community Psychiatry 1991; 42: 499-503.

58 Sar V, Akyuz G, Kundakci T, Kiziltan E, Dogan O. Childhood trauma, dissociation, and psychiatric comorbidity in patients with conversion disorder. Am J Psychiatry 2004; 161: 2271-6.

59 Tobin DL, Griffing AS. Coping, sexual abuse, and compensatory behavior. Int J Eat Disord 1996; 20: 143-8.

60 Whitlock J, Eckenrode J, Silverman D. Self-injurious behaviors in a college population. Pediatrics 2006; 117: 1939-48. 
61 Wright J, Friedrich W, Cinq-Mars C, Cyr M, McDuff F. Self-destructive and delinquent behaviors of adolescent female victims of child sexual abuse: rates and covariates in clinical and nonclinical samples. Violence and vict 2004; 19: 627-43.

62 Ystgaard M, Hestetun I, Loeb M, Mehlum L. Is there a specific relationship between childhood sexual and physical abuse and repeated suicidal behavior? Child Abuse Negl 2004; 28: 863-75.

63 Zanarini MC, Yong LMA, Frankenburg FR, Hennen J, Reich DB, Marino MF, Vjuanovic AA. Severity of reported childhood sexual abuse and its relation to severity of borderline psychopathology and psychosocial impairment among borderline inpatients. J Nerv Ment Dis 2002; 190: 381-7.

64 Zlotnick C, Shea MT, Pearlstein T, Simpson E, Costello E, Begin A. The relationship between dissociative symptoms, alexithymia, impulsivity, sexual abuse, and self-mutilation. Compr Psychiatry 1996; 37: 12-16.

65 Zoroglu SS, Tuzun U, Sar V, Tutkun H, Savas HA, Ozturk M, Alyanak B, Kora ME. Suicide attempt and self-mutilation among Turkish high schoo students in relation with abuse, neglect, and dissociation. Psychiatry Clin Neurosci 2003: 57: 119-26.

66 Zweig-Frank H, Paris J, Guzder J. Psychological risk factors for dissociation and self-mutilation in female patients with borderline personality disorder. Can J Psychiatry 1994; 39: 259-64.

67 Kraemer HC, Stice E, Kazdin A, Offord D, Kupfer D. How do risk factors work together? Mediators, moderators, and independent, overlapping, and proxy risk factors. Am J Psychiatry 2001; 158: 848-56.

68 Rind B, Tromovitch P, Bauserman R. A meta-analytic examination of assumed properties of child sexual abuse using college samples. Psychol Bull 1998; 124: $22-53$.

69 Klonsky ED, Muehlenkamp JJ. Self-injury: a research review for the practitioner. J Clin Psychol 2007; 63: 104556.

\section{Maudsley Hospital nightmares}

In his book, War Neurosis and Shell Shock (1919) Frederick Mott remarked on the importance of recurrent dreams whose content recalled combat experiences in the symptomatology of the psychological casualties of the Great War treated at the Maudsley. Here are two nightmares recalled by an infantry sergeant who had been a teacher in peacetime. The words in parentheses were added by Mott.

'I appeared to be resting on the roadside when a woman (unknown) called to me to see her husband's (a comrade) body which was about to be buried. I went to a field in which was a pit, and near the edge four or five dead bodies. In a hand cart near by was a legless body, the head of which was hidden by a slab of stone. (He had seen a legless body, which was covered with a Mackintosh sheet, which he removed). On moving the stone I found the body alive, and the head spoke to me, imploring me to see that it was not buried. Burial party arrived, and I was about to be buried with legless body when I awoke.

'After spending an evening with a brother (dead 11 years ago) I was making my way home when a violent storm compelled me to take shelter in a kind of culvert, which later turned into a quarry, situated between two houses. Men were doing blasting operations in the quarry, and whilst watching them I saw great upheavals of rock and eventually the building all around collapsed (explosion of a mine). Amongst the debris were several mutilated bodies, the most prominent of which was legless. I tried to proceed to get to the body, but found that I was myself pinned down by masonry which had fallen on top of me. As I struggled to get free the whole scene appeared to change to a huge fire, everything being enveloped in flames and through the flames I could still see the legless body which now bore the head of my wife, who was calling for me. I was struggling to get free when my mother seemed to be coming to my assistance, and I awoke to find the nurses and orderlies standing over me.'

Selected by Robert Howard, Professor of Old Age Psychiatry and Psychopathology, Institute of Psychiatry, King's College London 